\title{
Reintegração de Alunos do Ensino Técnico Integrado ao Ensino Médio e Técnico Concomitante para o Curso Superior no IFSP - Câmpus de Presidente Epitácio
}

DOI: 10.37702/2175-957X.COBENGE.2021.3534

matheus pereira - matheuspereiraifsp@gmail.com

IFSP

oscar pelegrine 174

19470-000 - presidente epitácio - SP

Ana Carolina Bueno Borges - ana.bueno@ifsp.edu.br

Instituto Federal de São Paulo

Rua Recife 1357

19470-000 - presidente epitácio - SP

Fernanda Cristina de Souza - Fernanda.souza@ifsp.edu.br

IFSP

RUA MANAUS 7-82

19470-000 - PRESIDENTE EPITÁCIO - SP

Resumo: A Educação das escolas técnicas é de grande importância social e educacional em nosso país, pois com ela pode se notar as premissas de educação de qualidade e formação de profissionais, que atuam no mercado de trabalho. Mas por trás deste esforço há um modo de construção social e educacional destes profissionais, que começa em sala de aula, vai se moldando, sendo construído com o tempo e com o conhecimento recebido pelos professores capacitados. Com base neste processo de formação de profissionais será abordado um estudo que trata de analisar e compreender o que se passa na vida acadêmica dos alunos durante sua formação técnica, para atuação no mercado de trabalho. As informações analisadas foram de uma pesquisa com alunos do curso Técnico Integrado em Mecatrônica e do Técnico Concomitante em Eletrotécnica. Também foram analisados a opinião e o ponto de vista dos alunos em questão se continuariam ou não na mesma instituição de ensino assim que terminassem o curso técnico partindo direto para um curso superior.

Palavras-chave: Curso Técnico, Engenharia Elétrica, Processo de Formação, 


\section{(C. COBENGE e IV Simpósio Internacional de Educação em Engenharia 2021 ie 28 a 30 de SETEMBRO

Instituto Federal de São Paulo. 


\section{COBENCE \\ 28 a 30 de SETEMBRO \\ REINTEGRAÇÃO DE ALUNOS DO ENSINO TÉCNICO INTEGRADO AO ENSINO MÉDIO E TÉCNICO CONCOMITANTE PARA O CURSO SUPERIOR NO IFSP - CÂMPUS DE PRESIDENTE EPITÁCIO}

\section{INTRODUÇÃO}

Segundo Paulo Freire (2000) A educação é permanente não porque certa linha ideológica ou certa posição política ou certo interesse econômico o exijam. A educação é permanente na razão, de um lado, da finitude do ser humano, de outro, da consciência que ele tem de sua finitude. Mais ainda, pelo fato de, ao longo da história, ter incorporado à sua natureza "não apenas saber que vivia mas saber que sabia e, assim, saber que podia saber mais. A educação e a formação permanente se fundam aí."

No Brasil, a educação, historicamente, tem sido funcional ao modelo de desenvolvimento econômico, fundamentado, na fase colonial, na exploração e expropriação de matéria-prima destinada às metrópoles europeias. Nesses primeiros séculos, tal modo de produção não exigia pessoal qualificado, de forma que não havia grandes preocupações com a educação das classes trabalhadoras, em função das tarefas que Ihes cabiam. Os primeiros indícios da Escola Profissional, como compreendida hoje, são do início do século XIX, quando se criou o Colégio das Fábricas. Ainda naquele século, foram criadas outras sociedades civis destinadas a dar amparo as crianças órfãs e abandonadas, possibilitando-lhes instrução teórico-prática e iniciando-as no ensino industrial. Portanto, as Escolas Profissionais originam-se predominantemente na sociedade civil e com objetivos assistencialistas. (MOURA, 2010).

A educação nos dias de hoje segue paradigmas sociais e subdesenvolvidos para seguimentos e práticas de ensino, contudo ao estudar as diretrizes educacionais do ensino médio e técnico entende-se que a educação dos jovens dos 15 aos 17 anos nas escolas técnicas é de ajuda visível e valorativa para a sua formação educacional e ou profissional. Os alunos que cursam as escolas técnicas são incentivados nos estudos de seus conteúdos básicos e específicos para que tenham um bom desempenho no decorrer da sua graduação. Mas com o decorrer do tempo pode-se observar que foi aplicado e incentivado em estudar conteúdos básicos e aprimorados em sala de aula para que os alunos tenham desde o ano inicial nas escolas técnicas um bom desempenho durante o decorrer da sua graduação.

Em 1909, Nilo Peçanha criou as Escolas de Aprendizes Artífices - destinadas aos pobres e humildes -, distribuindo-as em todo o país. Paralelamente, organizou-se o ensino agrícola para capacitar chefes de cultura, administradores e capatazes, o que evidenciou um redirecionamento da Escola Profissional, ampliando-se seu horizonte de atuação para atender aos interesses econômicos emergentes nos campos da agricultura e da indústria. (MOURA, 2010).

$\mathrm{Na}$ Lei 11.892 de 29/12/2008 que institui a criação dos Institutos Federais de Educação, Ciência e Tecnologia no Brasil, o Artigo $2^{\circ}$ estabelece que os Institutos Federais são instituições de educação superior, básica e profissional, pluricurriculares e multicampi, especializados na oferta de educação profissional tecnológica nas diferentes modalidades 
de ensino. Tendo por esse seguimento pode-se compreender o verdadeiro intuito do sistema de ensino dos Institutos Federais que é promover uma forma de educação básica e técnica de forma eficiente.

O Instituto Federal de São Paulo - Câmpus Presidente Epitácio - iniciou suas atividades em fevereiro de 2011 com os cursos técnicos nas áreas de Automação Industrial e Edificações, sendo uma instituição que oferta educação profissional nos níveis técnico e superior. Atualmente são ofertados os cursos técnicos concomitantes e subsequentes em Administração, Edificações e Eletrotécnica, como também os cursos técnicos integrado em Informática e Mecatrônica e os cursos superiores de Bacharelado em Ciência da Computação, em Engenharia Elétrica e Licenciatura em Pedagogia. Neste Instituto Federal há alunos que cursaram, ou que estão cursando, o ensino técnico que estão matriculados e frequentando os cursos superiores. Durante sua jornada como estudante de algum Câmpus vinculado ao Instituto Federal.

Se educando para educar o mundo, formamos bons homens e mulheres, mudando sua forma de enxergar a vida e os ensinando a pensar e não a decorar, como alguns outros sistemas de ensino pelo mundo a fora. Por outro lado, estudando a forma e o sistema de ensino da mesma e comparando a forma de como as escolas técnicas ajudaram e veem ajudando a construir bons cidadãos para a sociedade através da educação básica mais a formação técnica, nota-se a importância do estudo e da confirmação em que estes alunos obtiveram um bom resultado. Os cursos técnicos e superiores possuem objetivos diferentes.

O curso técnico tem como objetivo formar pessoas para o mercado de trabalho com uma formação mais prática. A Resolução $n^{\circ} 6$ de 20/09/2012, no Artigo 5ำ escreve a finalidade do curso técnico:

Os cursos de Educação Profissional Técnica de Nível Médio têm por finalidade proporcionar ao estudante conhecimentos, saberes e competências profissionais necessários ao exercício profissional e da cidadania, com base nos fundamentos científico tecnológicos, sóciohistóricos e culturais. (BRASIL, 2012, p. 2)

O curso superior permite que o aluno tenha uma visão mais ampla de conhecimento permitindo a formação, por exemplo, de pesquisadores ou cientistas. Na Lei de Diretrizes e Bases nำ 9.394 de 20/12/1996, no Artigo 43 são apresentadas as finalidades da educação superior:

I - Estimular a criação cultural e o desenvolvimento do espírito científico e do pensamento reflexivo;

II - Formar diplomados nas diferentes áreas do conhecimento, aptos para a inserção em setores profissionais e para a participação no desenvolvimento da sociedade brasileira, e colaborar na sua formação contínua.

III - incentivar o trabalho de pesquisa e investigação científica, visando o desenvolvimento da ciência e da tecnologia e da criação e difusão da cultura, e, desse modo desenvolver o entendimento do homem e do meio em que vive; IV - promover a divulgação de conhecimentos culturais, científicos e técnicos que constituem patrimônio da humanidade e comunicar o saber através do ensino, de publicações ou de outras formas de comunicação; 
V - Suscitar o desejo permanente de aperfeiçoamento cultural e profissional e possibilitar a correspondente concretização, integrando os conhecimentos que vão sendo adquiridos numa estrutura intelectual sistematizadora do conhecimento de cada geração;

VI - Estimular o conhecimento dos problemas do mundo presente, em particular os nacionais e regionais, prestar serviços especializados à comunidade e estabelecer com esta uma relação de reciprocidade;

VII - promover a extensão, aberta à participação da população, visando à difusão das conquistas e benefícios resultantes da criação cultural e da pesquisa científica geradas na instituição." (BRASIL, 1996, p. 20-21)

Logo, foram feitas pesquisas de campo com os alunos do ensino técnico integrado do curso Técnico em Mecatrônica do IFSP-PEP e também com os alunos do curso técnico concomitante em Eletrotécnica. Um dos objetivos do trabalho é compreender o porquê desses alunos estarem estudando neste Câmpus e avaliar a sua perspectiva de futuro, após concluírem o curso. Nesse sentido também será apresentado neste trabalho os alunos que estudam no Instituto Federal, e que pretendem ingressar em um ensino superior no mesmo Câmpus de origem. Além disso serão apresentados dados de uma pesquisa quantiqualitativa mostrando os dados do tema proposto.

\section{MATERIAIS E MÉTODOS}

O método de pesquisa utilizado para tratar este tema abordado foi um questionário contendo algumas perguntas relevantes para construir uma base de dados, possui assuntos do grau de interesse dos alunos pela unidade de ensino ao qual pertencem e, querendo saber e entender o que eles pensam quando se fala sobre o curso técnico integrado em Mecatrônica e o curso técnico concomitante em Eletrotécnica. Como o levantamento de dados foi realizado durante a pandemia da COVID-19, a pesquisa de "campo" foi online. Aplicou-se um questionário via google forms onde os alunos responderam as seguintes perguntas:

- Quantos anos de idade você tem?

- Porque está matriculado no IFSP?

- Em qual ano você está matriculado atualmente?

- O por quê você está matriculado no IFSP?

- Você pretende continuar a estudar na mesma instituição assim que acabar o seu curso atual?

- Por que continuar a estudar na mesma instituição?

- Você tem facilidade com as matérias ofertadas no currículo do seu curso?

- O que pretende fazer assim que terminar o seu curso no IFSP?

\section{RESULTADOS E DISCUSSÃO}

O total de alunos que responderam à pesquisa referente ao curso técnico em Mecatrônica foram 85. Os correspondentes que responderam à esta pesquisa são alunos de uma faixa etária de 14 a 18 anos de idade. E referente também ao curso técnico 
concomitante em Eletrotécnica, foram respondidas essas mesmas perguntas. Ao quanto de pessoas que responderam foram obtidas no total 43 pessoas.

O trabalho possui três principais focos de discussão que foram analisados utilizando gráficos. Primeiro foi feita uma análise detalhada no curso integrado em Mecatrônica e por seguimento no curso técnico concomitante em Eletrotécnica. Primeiro foi analisado o curso técnico integrado em Mecatrônica.

Buscando saber o ano em que os entrevistados estão matriculados nos cursos do IFSP - Câmpus Presidente Epitácio - foi obtido um percentual de 48,2\% de alunos matriculados no primeiro ano de curso técnico, 38,8\% de alunos matriculados no segundo ano de curso técnico e $12,9 \%$ de alunos matriculados no terceiro ano de curso técnico. De acordo com o Gráfico 1, pode-se perceber como um número grande em destaque de entrevistados o primeiro ano do curso técnico em mecatrônica representou grande parte desta entrevista.

Gráfico 1 - Ano que o aluno do curso técnico integrado em Mecatrônica está matriculado.
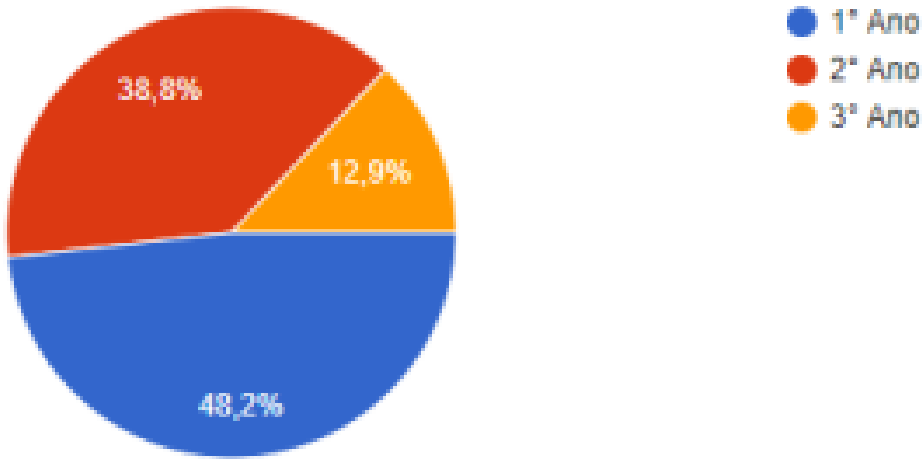

Fonte: Autor

No Gráfico 2, sobre a questão de facilidade com as disciplinas ofertadas no curso de Mecatrônica, mostra uma baixa porcentagem de alunos que não tenham facilidade com algumas disciplinas, contabilizando uma porcentagem de $18,8 \%$, embora os outros dados tenham que ser pensados e levados em consideração sobre a preparação destes alunos antes de ingressar no IFSP. Como por exemplo: o sistema de ensino das escolas públicas não prepara os alunos para um sistema de ensino técnico. Sendo assim, a porcentagem de alunos que tenham uma certa facilidade com as matérias do curso seja de $23,5 \%$, com base no sistema de ensino do IFSP seja "puxado", devemos levar em consideração, por exemplo: a forma de como esses alunos estudam e se preparam para compreender as matérias de seu curso. Entretanto a parte de alunos que talvez tenham uma certa facilidade com as disciplinas do seu curso de origem seja alta, com uma porcentagem de $57,6 \%$, deve-se levar em consideração o interesse e o foco destes alunos, como por exemplo: a formação educacional destes alunos vindos de casa, quais são as regras de estudo de cada ambiente familiar, se tem o tempo de estudar e o tempo de descanso, ambos esses pontos são bem vistos e bem vindos quando analisando esta porcentagem. 
Gráfico 2 - Facilidade com as disciplinas do curso técnico integrado em Mecatrônica.

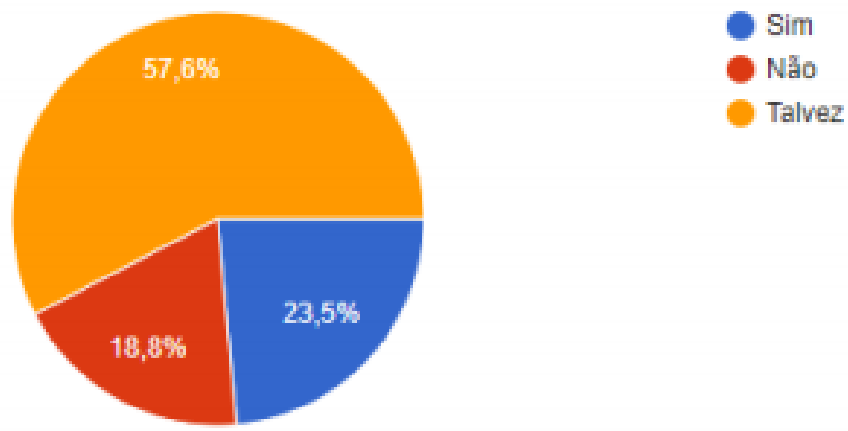

Fonte: Autor

No Gráfico 3, quando se pergunta sobre a continuação dos entrevistados na mesma instituição de ensino assim que terminar o seu curso de origem, percebe-se que a grande porcentagem da opção talvez tenha sido a mais listada com $48,2 \%$. Isso mostra que alguns alunos têm uma visão ampla do sistema de ensino do IFSP porque acreditam que podem continuar no IFSP. Já a opção que questiona se os alunos não continuariam no IFSP obteve uma porcentagem significativa de $36,5 \%$. Por fim a opção de sim para os alunos que pretendem continuar no IFSP assim que terminarem o seu curso de origem foi de $15,3 \%$. Analisando a opção "talvez" e "sim", mostra-se que o sistema de ensino ofertado pelo IFSP - Câmpus de Presidente Epitácio - é valorativo a ser continuado e estendido até sua graduação.

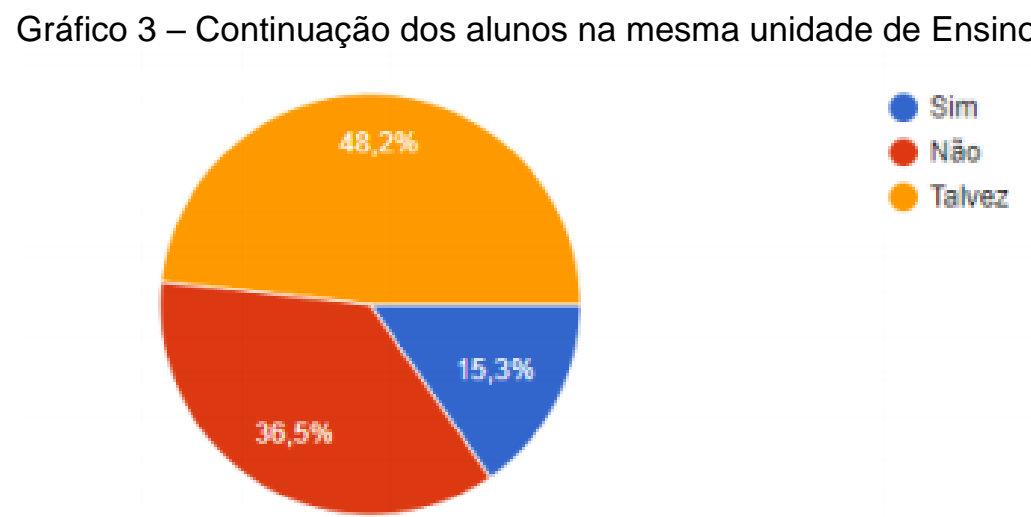

Fonte: Autor

Por este seguimento agora serão apresentados os dados referentes a pesquisa com o curso técnico concomitante em Eletrotécnica, com o mesmo intuito de pergunta referente a primeira análise realizada na parte do curso técnico integrado. No Gráfico 4, buscou-se entender em que ano os entrevistados estão matriculados. Os dados obtidos foram de 43 entrevistados, sendo $76,7 \%$ alunos matriculados no $1^{\circ}$ módulo do curso e $23,3 \%$ de alunos matriculados no $3^{\circ}$ módulo. Não obteve respostas referentes ao $2^{\circ}$ e 4ํㅡㅁódulos porque não estavam sendo ofertados quando a pesquisa foi realizada. 
Gráfico 4 - Ano que o aluno do curso técnico concomitante em Eletrotécnica está matriculado.

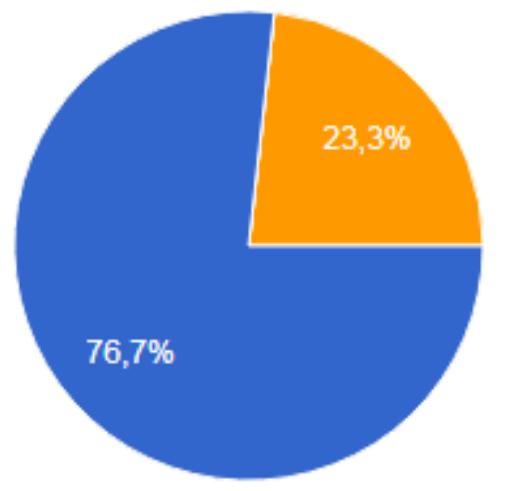

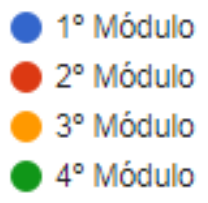

Fonte: Autor

No Gráfico 5 obteve-se 43 respostas referente a pergunta sobre a facilidade dos alunos com as disciplinas em geral do curso. As perguntas foram básicas como: sim, não, talvez e por seguimento 9 alunos não responderam esta parte do questionário.

\section{Gráfico 5 - Facilidade com as disciplinas do curso técnico em Eletrotécnica.}

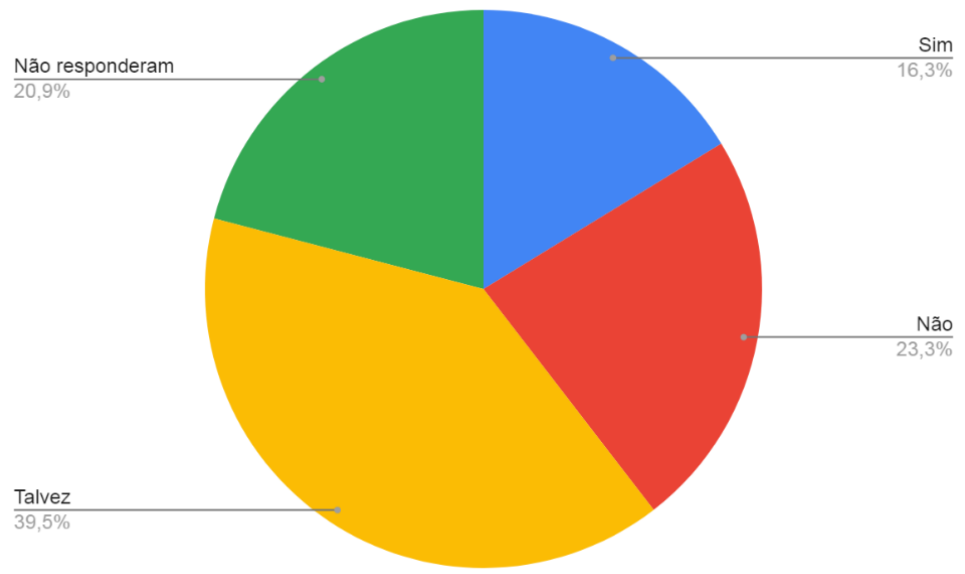

Fonte: Autor

Analisando os resultados obtidos no Gráfico 5, algumas dúvidas questionadas podem ser esclarecidas, sobre a facilidade dos alunos em relação as disciplinas ofertadas no seu período de curso. O resultado obtido foi de grande estima para a construção de uma base de dados onde obtemos os seguintes aspectos: $20,9 \%$ dos entrevistados não responderam esta pergunta, $16,9 \%$ dos entrevistados responderam que "sim", tem uma facilidade com as disciplinas ofertadas em seu curso e respectivamente as que estão sendo ofertadas em seu respectivo semestre de curso. Já $23,3 \%$ dos alunos entrevistados disseram que "não" tem facilidade com as disciplinas ofertadas em seu curso. E por fim $39,5 \%$ dos entrevistados disseram que "talvez" tenham uma certa facilidade com as disciplinas ofertadas em seu curso. Deste modo, os alunos que responderam "sim" $(16,3 \%)$ e "talvez" (39,5\%), totalizam a maioria, apontando a questão de terem facilidade com as disciplinas do curso técnico em Eletrotécnica.

Para finalizar esse estudo foi perguntado de forma simplificada o que o aluno entrevistado pretendia fazer assim que terminasse o seu curso técnico, ainda nos referindo ao curso técnico concomitante e subsequente em Eletrotécnica, obtivemos de forma 
simplificada que $50 \%$ dos entrevistados querem trabalhar na sua área de formação. $\mathrm{E} 40 \%$ querem cursar a faculdade de engenharia e os demais $10 \%$ ainda não sabem o que fazer ou não responderam a pergunta.

Os dados obtidos através da pesquisa de campo mostrou-se congruentes aos objetivos apresentados no início deste trabalho. Por seguimento os alunos do curso técnico integrado em Mecatrônica quando responderam ao questionário referente a cursar um ensino superior não foram tão precisos quanto aos alunos do curso técnico em Eletrotécnica, pois responderam somente que iriam cursar um ensino superior, mas não o especificaram qual. Por fim, pode se compreender a importância do ensino técnico na vida dos indivíduos que contribuíram para a realização deste trabalho e como a sua jornada de ensino no IFSP - Câmpus Presidente Epitácio, os tornaram indivíduos pensantes e capacitados que aprenderam a ter os valores morais e teóricos de uma capacitação social promissora.

\section{CONCLUSÃO}

$\mathrm{Na}$ pesquisa realizada investigou o porquê dos alunos que cursam o técnico integrado em Mecatrônica e técnico concomitante em Eletrotécnica estudam na instituição e se pretendem cursar um curso de graduação no IFSP - Câmpus Presidente Epitácio.

Após o levantamento de dados, observou que a maioria dos alunos que cursam o ensino técnico concomitante em Eletrotécnica pretendem continuar na mesma instituição de origem, sendo que $40 \%$ dos alunos entrevistados pretendem ingressar no curso de Bacharelado em Engenharia Elétrica. Após a pesquisa de campo com base nas respostas do curso técnico integrado em Mecatrônica percebe-se também que o percentual de alunos que pretendem continuar estudando na instituição de ensino é de $40 \%$. Estes dados mostra o valor e a importância dos cursos técnicos na formação de novos profissionais na sociedade.

A contribuição deste trabalho é para que as pessoas conheçam o que é a educação nas escolas técnicas e assim compreendendo o porquê ela é considerada de grande importância nos parâmetros sociais. Este trabalho tem por meio de segmentos e tópicos reais dos padrões vividos em sala de aula ou até mesmo fora dela. Então ao estudar este tema pode-se cronometrar e instituir os conceitos básicos sociais da educação envolvendo as escolas públicas federais do estado de São Paulo, ou até mesmo do País, buscando compreender se o aluno tem um bom desempenho durante sua vida acadêmica ou não. Como trabalho futuro espera-se que as pessoas entendam que a educação nas escolas técnicas deve ser um direito de todos não sucumbindo os meios de exclusão social e intelectual dos jovens.

\section{REFERÊNCIAS}

BRASIL. Conselho Nacional de Educação. Resolução CNE/CEB n 6, de 20 de setembro de 2012. Define Diretrizes Curriculares para a Educação Profissional. D.O.U., Brasília, 21 set. 2012.

BRASIL. Lei de Diretrizes e Bases da Educação Nacional. Lei número 9394, 20 de dezembro de 1996.

BRASIL. Lei no 11.892, de 29 de dezembro de 2008. Institui a Rede Federal de Educação Profissional, Científica e Tecnológica, cria os Institutos Federais de Educação, Ciência e 
Tecnologia, e dá outras providências. D.O.U. Seção 1, de 30 de dezembro de 2008. Brasília, DF, 2008.

BRASIL. Ministério da Educação. Instituto Federal de Educação, Ciência e Tecnologia de São Paulo. Projeto Pedagógico Do Curso Superior De Bacharelado Em Ciência da Computação. Presidente Epitácio. Setembro / 2017.

BRASIL. Ministério da Educação. Instituto Federal de Educação, Ciência e Tecnologia de São Paulo. Projeto Pedagógico Do Curso Superior De Bacharelado Em Engenharia De Elétrica. Presidente Epitácio. Setembro / 2016.

BRASIL. Ministério da Educação. Instituto Federal de Educação, Ciência e Tecnologia de São Paulo. Projeto Pedagógico Do Curso Superior De Licenciatura em Pedagogia. Presidente Epitácio. Setembro / 2016.

BRASIL. Ministério da Educação. Instituto Federal de Educação, Ciência e Tecnologia de São Paulo. Projeto Pedagógico Do Curso Técnico Em Eletrotécnica. Presidente Epitácio. Julho / 2014.

BRASIL. Ministério da Educação. Instituto Federal de Educação, Ciência e Tecnologia de São Paulo. Projeto Pedagógico Do Curso Técnico Em Informática Integrado ao Ensino Médio. Presidente Epitácio. Julho / 2015.

BRASIL. Ministério da Educação. Instituto Federal de Educação, Ciência e Tecnologia de São Paulo. Projeto Pedagógico Do Curso Técnico Em Mecatrônica Integrado ao Ensino Médio. Presidente Epitácio. Julho / 2015.

BRANDÃO, Carlos da Fonseca. LDB passo a passo: Lei de diretrizes e bases da educação nacional, Lei n. 9.394/96, comentada e interpretada, artigo por artigo. 4. ed. atual. São Paulo: Avercamp, 2009.. 191 p.

FREIRE, P. (2000). Política e educação: ensaios (Coleção Questões de Nossa Época). São Paulo: Cortez. (Original publicado em 1993)

MOURA, D. H. (2010). A relação entre a educação profissional e a educação básica na CONAE 2010: possibilidades e limites para a construção do novo Plano Nacional de Educação. Educação e Sociedade, n. 112, v. 31, 875-894.

SAVIANI, Dermeval. A lei da educação: LDB: trajetória, limites e perspectivas. 13. ed. rev., atual. e ampl. Campinas: Autores Associados, 2016. 283 p. (Coleção educação contemporânea).

SANTOS, Roberto Hugo Melo; COSTA JÚNIOR, Ademar Gonçalves; ARAÚJO JÚNIOR, Ruy de Aguiar. Implantação das atividades complementares no curso de engenharia elétrica, do IFBA Câmpus Vitória da Conquista - Um estudo de caso. XXXIX Congresso Brasileiro de Educação em Engenharia, 2011, Blumenau - SC. 
Abstract: The education of technical schools is of great social and educational importance in our country, as it can be seen the premises of quality education and training of professionals, who work in the labor market. But behind this effort there is a way of social and educational construction of these professionals, which begins in the classroom, is shaped, being built over time and with the knowledge received by trained teachers. Based on this professional training process, a study will be approached that seeks to analyze and understand what goes on in the academic life of students during their technical training, to work in the labor market. The information analyzed was from a survey of students from the Mechatronics Integrated Technician course and the Concurrent Technician in Electrotechnics. The opinion and the point of view of the students in question were also analyzed, whether or not they would continue at the same educational institution as soon as they finished the technical course, leaving directly for a higher education course.

Keywords: Technical Course, Electrical Engineering, Training Process, Federal Institute of São Paulo. 